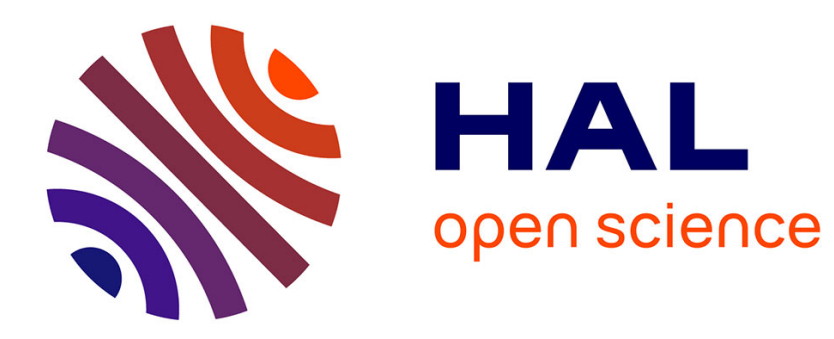

\title{
CHARGED GRAIN-BOUNDARIES IN n-Ge BICRYSTALS
}

X. Wu, V. Szkielko, P. Haasen

\section{To cite this version:}

X. Wu, V. Szkielko, P. Haasen. CHARGED GRAIN-BOUNDARIES IN n-Ge BICRYSTALS. Journal de Physique Colloques, 1982, 43 (C1), pp.C1-135-C1-139. 10.1051/jphyscol:1982119 . jpa-00221775

\section{HAL Id: jpa-00221775 https://hal.science/jpa-00221775}

Submitted on 1 Jan 1982

HAL is a multi-disciplinary open access archive for the deposit and dissemination of scientific research documents, whether they are published or not. The documents may come from teaching and research institutions in France or abroad, or from public or private research centers.
L'archive ouverte pluridisciplinaire HAL, est destinée au dépôt et à la diffusion de documents scientifiques de niveau recherche, publiés ou non, émanant des établissements d'enseignement et de recherche français ou étrangers, des laboratoires publics ou privés. 
X.J. Wu*, V. Szkielko ${ }^{+}$and P. Haasen

Institut flir Metallphysik, Universität Göttingen and Sonderforschungsbereich, 126 Gottingen/Clausthal, E.R.G.

Résumé.- Nous avons fait crôtre des bicristaux de germanium avec deux types de joint de flexion à faible énergie, $\Sigma 9$ et $\Sigma 11$ (d'après la classification du modèle CSL). Les courantvoltage caractéristiques des joints de grains ont été mésurés dans un domaine de temperature entre $77 \mathrm{~K}$ et $420 \mathrm{~K}$. Nous trouvons des barrières de potentiel seulement pour des joints du type $\Sigma 11$ dans le germanium du type $n$, ce qui confirme des prédictions sur la structure atomique de ces joints [1].

Les résultats experimentaux permettent la conclusion que la charge électronique des joints $\Sigma 11$ est capturée par un défaut du réseau avec un niveau d'energie d'environ $0,2 \mathrm{eV}$ au dessus du sommet de la bande de valence.

Abstract.- Gexmanium bicrystals with two types of low-energy symmetric tilt boundaries, $\Sigma 9$ and $\Sigma 11$ (CSI model classification) were grown. Current-voltage characteristics of grainboundaries were measured in the temperature range $77 \mathrm{~K} \div 420 \mathrm{~K}$. Potential barriers were found only at $\Sigma 11$ boundaries in $\mathrm{n} G$ which confirms the theoretical predictions of the atomic structure of these boundaries [1]. From the experimental data the conclusion is drawn that the electronic charge of $\Sigma 11$ boundaries is captured at the lattice defect with the energy level of about $0.2 \mathrm{eV}$ above the top of the valence band.

The analysis of the atomic structure of grain-boundaries in the diamond lattice given by Möller [1] predicts low energy "special" boundaries

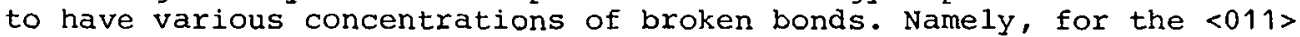
symmetric tilt boundaries classified in the coincidence site lattice, model as $\Sigma 11$ (rotation axis $\langle 110\rangle$, rotation angle $\theta=129^{\circ}$ ) the concentration of broken should be as high as $\sim 10^{15} \mathrm{~cm}^{-3}$ while for $\Sigma 9$ (rotation axis $\langle 110\rangle, \theta \approx 39$, a perfect bond saturation occurs. In semiconducting materials this difference should lead to drasticaliy different electric properties of grain boundaries.

A verification of this prediction is the aim of present paper. To minimize the effect of decoration of the grain boundaries by impurities (mostly oxygen) germanium was chosen as a model material. Because of its relatively small energy gap and the high potential barriers developing at charged boundaries attention is given to the barrier screening.

Experiment.- Bicrystals with the common rotation axis $\langle 110\rangle$ and two types of symmetric tilt boundaries $\Sigma 9$ and $\Sigma 11$ were grown using a two seed Crochalski method. The relative grain orientations in the bicrystals were more accurate than $2^{\circ}$. Both $p-$ and n-type bicrystals doped during growth were investigated. Bulk, rectangular samples (3.5 $\left.\times 3.5 \times 25 \mathrm{~mm}^{3}\right)$, with the long axis perpendicular to the grainboundary were cut out. The carrier concentration was measured by Hall

* on leave from : Institute of Metal Research, Academica Sinica, Shenyang, China

on leave from : Institute of Physics, Polish Academy of Sciences, Poland 
effect in every sample. Samples with various carrier concentrations in the range $10^{14} \div 5 \cdot 10^{17} \mathrm{~cm}^{-3}$ were investigated.

Current contacts and small potential probes were prepared on both sides of the grain-boundary using a Ga-Al amalgam. With a DC current flowing along the sample, perpendicularly to the grain boundary, the voltage drop between the potential probes was measured. During measurements the sample was in an helium atmosphere with stabilized temperature. Various surface treatments and sample cross-sections were tried to exclude an effect of a surface conductivity on the experimental results.

Results and discussion.- When an electric current $J$ flows through the sample, the potential barrier at a charged grain boundary results in an additional voltage drop over grain boundary which is calculated from the sample geometry and the voltage measured between the potential probes. Potential barriers were detected only at $\Sigma 11$ boundaries in n-type samples. The effect of $\Sigma 11$ boundary in p-type and of $\Sigma 9$ boundary in both $p$ - and n-type germanium on the sample conductance, if any, was below the detection limit ( $q \phi \sim k T)$.

The J-V characteristics ( $V$ is the voltage drop over the grain-boundary) for all charged $\Sigma 11$ boundaries show three regions: a) an ohmic one (for $\mathrm{V}<2 \mathrm{kT}$ ), b) region of current saturation, and c) a region of soft breakdown (Fig. 1). As a rule some small asymmetry appears for opposite biases. The J-V curve can generally be described by

$$
J=J_{\mathbf{s}}(\mathrm{V})[1-\exp (-\mathrm{q}|\mathrm{V}| / \mathrm{kT})]
$$

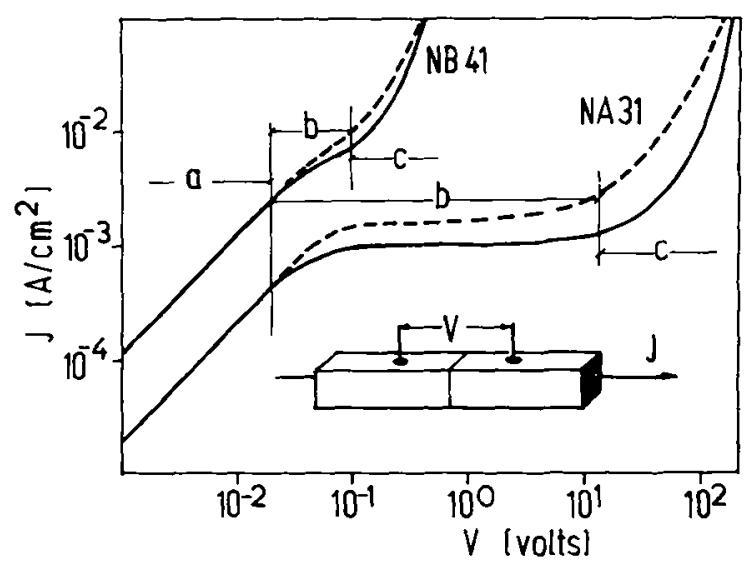

Fig 1.- Typical J-V characteristics of charged grain boundaries and a scheme of the sample geometry.

The saturation current $J_{S}(V)$ is in the two first regions weakly dependent on the voltage and slightly increases with sample doping. The voltage at which a pronounced breakdown appears decreases with increasing sample doping.

A zero-bias conductance of the grain-boundary can be defined as $G$ $\mathrm{G}_{0}=\mathrm{q} \mathrm{J}(\mathrm{O}) / \mathrm{kT}$. $\mathrm{G}_{0}$ is proportional to $\exp \left(-\mathrm{E}_{\mathrm{ACT}} / \mathrm{kT}\right)$ in the temperature range from about $200 \mathrm{k}$ up to intrinsic temperacure with an activation energy $E_{A C T} \approx 0.65 \mathrm{eV}$ for all charged boundaries (Fig. 2). Below

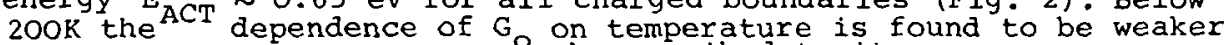
and no activation energy can be ascribed to it.

The obtained value of $\mathrm{E}_{\mathrm{ACT}}$ deviates clearly from $\mathrm{Eq} / 2$ which is expected for a current ${ }^{A C T}$ determined by generation of minority carriers. The current of majority carriers over the potential barrier in high mobility semiconductors is adequately described by the thermionic emission theory (TET) [2]. For the current of carriers reaching the top of the potential barrier $\phi$, TET gives: 


$$
J_{S}=A^{*} T^{2} e^{-(q \phi+\zeta) / k T}
$$

where $A^{*}$ is the effective Richardson constant and $\zeta$ is the energy difference between the Fermi level and the bottom of the condution band. Assuming that only a negligibly small portion of this current is trapped at the grain-boundary one obtains for the zero-bias conductance

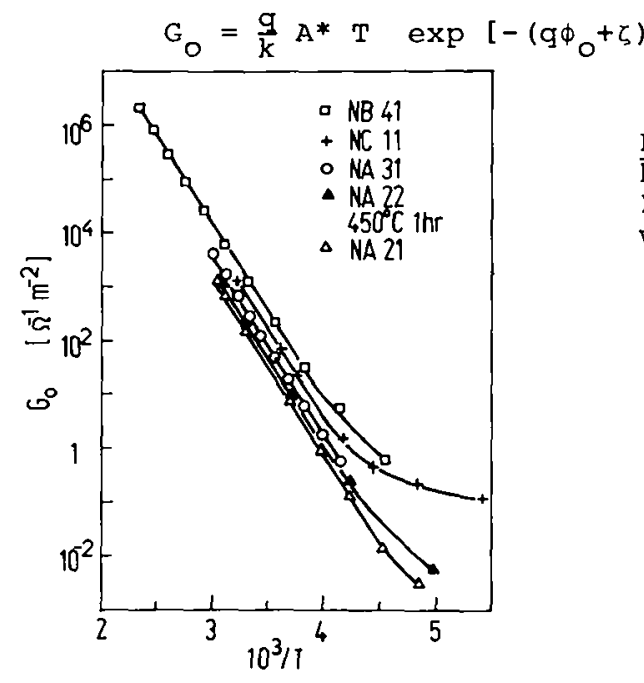

$$
\begin{aligned}
& \text { Fig. 2.- Dependence of the zero- } \\
& \text { bias conductivity Go of charged } \\
& \Sigma 11 \text { grain boundaries in samples } \\
& \text { with various doping levels } \\
& \text { (NB } 41-4 \cdot 7 \cdot 10^{17} \mathrm{~cm}^{-3} \text {, } \\
& \text { NC } 11-10^{15} \mathrm{~cm}^{-3}, \\
& \text { NA } 31-2 \cdot 5 \cdot 10^{14} \mathrm{~cm}^{-3}, \\
& \text { NA } 21-2 \cdot 10^{14} \mathrm{~cm}^{-3}, \\
& \text { NA } 22-2.2 \cdot 10^{14} \mathrm{~cm}^{-3} \text {, the sample } \\
& \text { annealed and quenched). }
\end{aligned}
$$

From the activation energy $\mathrm{E}_{\mathrm{ACT}}$ only the temperature independent part of $\phi_{0}$ can be calculated. Therfore, to estimate $\phi_{0}$ completely the theoretical value of the effective Richardson constant

$A^{*}=142 \mathrm{~A} \mathrm{~cm} \mathrm{~cm}^{-2} \mathrm{~K}^{-2}$ (with an isotropically averaged conductivity effective mass of electrons) is used. From the experimental data both $\phi_{o}$ and $E_{0}$, the Fermi level position at the grain-boundary relative to the valence band (see Fig. 3), are calculated for every temperature.

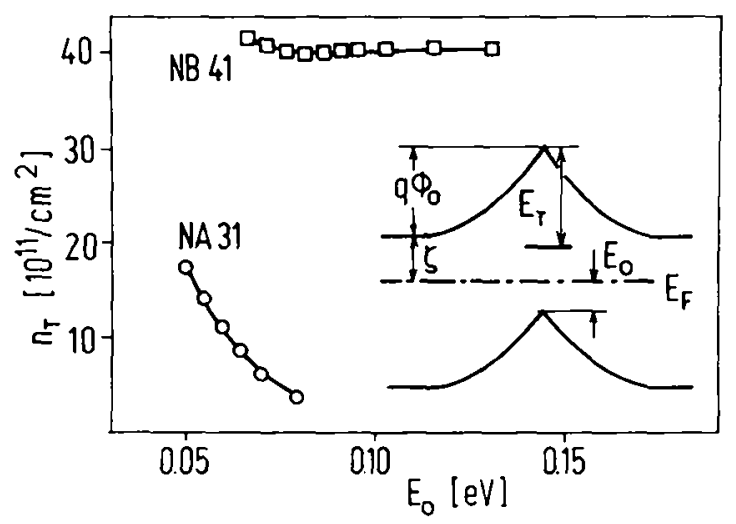

Fig. 3.- Dependence of the concentration of electrons trapped in grain-boundary states on the Fermi level position $\mathbf{E}_{\mathrm{O}}$. (The band scheme explains the defined quantities).

It is worth pointing out that the screening of the barrier charge can not be calculated using the depletion approximation since $E_{0}<\zeta$, in the measured temperature range even for the sample with the highest doping $\left(5 \cdot 10^{17} \mathrm{~cm}^{-3}\right)$. To relate the height of the potential barrier to the electronic charge trapped in grain-boundary states minority carrier screening of the potential (inversion) must be taken into account as it was done in [3]. In the rigid band approximation the planar charge of the electrons inducing the barrier $\phi$ at the grain-boundary is given by 


$$
Q_{e}=q n_{T}=2 q\left(\frac{2 \varepsilon \varepsilon_{O} N_{D}}{q^{2} k T}\right)^{\frac{1}{2}}\left[\beta \phi-1+e^{-\beta \phi}+\frac{n i^{2}}{N_{D}^{2}} e^{\beta \phi}\right]^{\frac{1}{2}}
$$

where $\mathrm{N}_{\mathrm{p}}$ is the donor concentration, $\varepsilon \varepsilon_{\mathrm{o}}$ is the dielectric permitivity of the crystal, $\beta=\mathrm{q} / \mathrm{kT}$.

Using this formula $n_{\mathrm{T}}$ is calculated for every temperature for the experimental values of $\phi_{O}$ and plotted in $\mathrm{Fig} .3$ as a function of $\mathrm{E}_{\mathrm{O}}$ for two samples with widely different doping levels. If the energy distribution of grain-boundary states, $g(E)$ differs from zero for $E=E_{O}$ then in the step-like approximation for the Fermi function $\partial \mathrm{n}_{\mathrm{T}} / \partial \mathrm{E}_{\mathrm{O}}=\mathrm{g}\left(\mathrm{E}_{\mathrm{O}}\right)$. From $\mathrm{Fig} .3$ it is clear that in fact $\partial \mathrm{n}_{\mathrm{T}} / \partial \mathrm{E}_{O} \leq \mathrm{O}$, i.e. $g\left(E_{O}\right)=0$ in the whole range of experimentally obtained $E_{O}$. Moreover, the grain boundary states controlling the barrier charge must be located at energies above $\mathrm{E}_{\mathrm{O}} \max$.

Assuming that $g(E) \neq 0$ only for energies satisfying the condition $\left(E-E_{0}\right)>2 \mathrm{kT}$, the Boltzmann approximation can be used and an effective density of states $N_{T}$ with a single energy level, $E_{T}$, can be introduced.

In terms of this single level the areal concentration of electrons trapped at the grain boundary is

$$
\mathrm{n}_{\mathrm{T}}=\mathrm{N}_{\mathrm{T}} \exp \left[-\left(\mathrm{E}_{\mathrm{g}}-\mathrm{E}_{\mathrm{T}}-\mathrm{E}_{\mathrm{O}}\right) / \mathrm{kT}\right]
$$

which multiplied by exp $\left(-E_{O} / \mathrm{kT}\right)$ gives

$$
n_{T} \exp \left(-E_{O} / k T\right)=N_{T} \exp \left[-\left(E_{G}-E_{T}\right) / k T\right]^{2}
$$

The left side of this equation is calculated from the experimental data for two samples with dopings differing by more than 3 orders of magnitude and given in Fig. 4 as a function of the inverse temperature. Experimental points can be fitted at higher temperature (smaller $\mathrm{E}_{\mathrm{O}}$, where the Boltzmann approximation is better fulfilled) by a straight

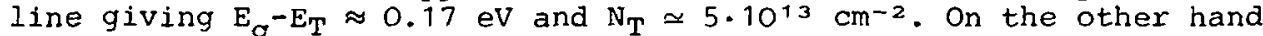
at higher temperatures predominant barrier screening by minority carriers is expected and eq. (4) can be roughly approximated by

$$
\mathrm{n}_{\mathrm{T}}=2\left(\frac{2 \varepsilon \varepsilon_{\mathrm{O}} \mathrm{N}}{\mathrm{q}^{2 / \mathrm{kT}}}\right)^{\frac{1}{2}} \frac{\mathrm{n}_{i}}{\mathrm{~N}_{\mathrm{D}}} \mathrm{e}^{q \phi_{\mathrm{O}} / 2 \mathrm{kT}}
$$

Recalling that $E_{O}=E_{q}-q \phi_{O}-\zeta$ (see Fig. 3) one can generally solve eqs. (5) and (6) for $\mathrm{q}_{\phi_{0}}$, which substituted into the TET expression (3) gives for Go:

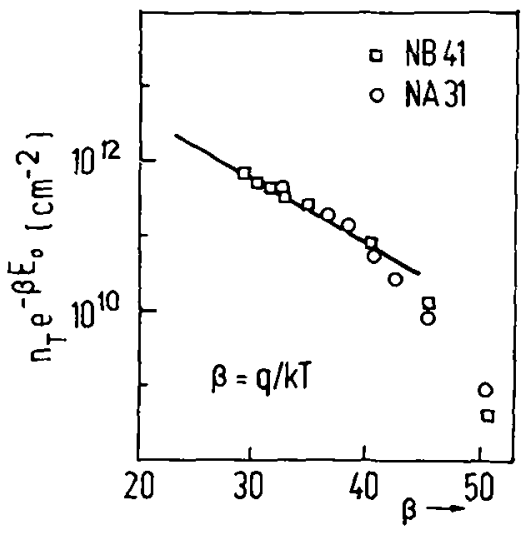

Fig. 4.- Dependence of the left side of eq. (7) on the inverse temperature. 


$$
G o=A * T \frac{g}{k}\left(\frac{N_{T}{ }^{2} g^{3}}{8 \varepsilon \varepsilon_{O} N_{v}}\right)^{\frac{1}{3}} \cdot e^{-\frac{1}{k} \frac{\partial E_{g}}{\partial T}} e^{-E_{A C T} / k T}
$$

where $\mathrm{E}_{\mathrm{ACT}}=\frac{2}{3} \mathrm{E}_{\mathrm{T}_{0}}+\frac{1}{3} \mathrm{E}_{\mathrm{go}} \cdot \mathrm{E}_{\mathrm{T}_{\mathrm{O}}}$ and $\mathrm{E}_{\mathrm{go}}$ are the values of $\mathrm{E}_{\mathrm{T}}$ and $\mathrm{E}_{\mathrm{g}}$ extrapolated to zero temperature. Eq. (7) gives a doping independent $\mathrm{G}_{\mathrm{O}}$ (the experimentally observed weak dependence can be explained by carrier scattering in the space-charge region) and Go proportional to $\mathrm{N}_{\mathrm{T}}^{-2 / 3}$. Assuming that the grain-boundary trap level is bound to the valence band $\mathrm{E}_{\mathrm{g}}-\mathrm{E}_{\mathrm{T}}=0.20 \mathrm{eV}$ is obtained from the experimental value of $E_{\mathrm{ACT}}$.

Conclusions.- The analysis of the high temperature zero bias conductivity of charged $\Sigma 11$ boundaries gives the general conditions for a single activation energy in the dependence of $G_{O}$ on temperature. These are the existence of a high concentration of almost empty states at the grain boundary (which makes the Boltzmann statistics applicable) and a strong screening of the barrier charge by minority carriers. Similar features are observed in $G_{O}(T)$ and measured with DLTS as a trap energy $\mathrm{E}_{\mathrm{T}}=0.45 \mathrm{eV}$ for smal1 angle grain boundaries in Ge [4]. This suggests that in both cases there is a common structural defect with a single trap level about $0.2 \mathrm{eV}$ above the valence band. The fact that no barrier is detected with $\Sigma 9$ boundaries confirms Möller's prediction and shows that the defect should be an intrinsic one. No barriers are observed in pGe at $\Sigma 11$ boundaries. This points towards an acceptor character of the defect.

The "apparent pinning" of the Fermi level in charged boundaries at $E_{0} \approx 0.1 \mathrm{eV}$ is due to simultaneous effect of a high trap density and a strong inversion layer at the boundary. The effect of at the inversion layer must be carefully considered in the analysis of both stationary (dc J-V characteristics) and nonstationary (ac conductivity, capacitance) phenomena at charged boundaries in Ge.

\section{References.-}

[1] MÖLLER H.-J., Phi1. Mag. A43 (1981) 1045.

[2] SZE S.M., Physics of Semicond. Devices, wiley-Interscience 1969.

[3] BRONIATOWSKI A., J. Physique 42 (1981) 741.

[4] BRONIATOWSKI A., BOURGOUIN J.C., MRS Conf. Boston, North Holland, New York 1981, p. 119 